\title{
Respiratory Pathologies Associated with Obesity
}

\author{
Alcibey Alvarado* \\ Internal Medicine and Neumology, Clínica de Diagnóstico Médico, San José, Costa Rica
}

\begin{abstract}
The prevalence of obesity worldwide is increasing and future projections predict that, by the year 2030, the number of obese people will exceed one billion individuals, that is, $15-20 \%$ of the world population. This pandemic is associated with multiple medical complications such as cardiovascular, metabolic, renal, psychological, neoplastic, musculoskeletal and respiratory disorders. The latter include obstructive sleep apnea (OSA), hypoventilation-obesity syndrome (OHS) and the asthma phenotype associated with obesity. This monograph covers these topics in a concise manner, highlighting the physiopathology, the clinical picture and the treatment. The fundamental objective is to dissect the interrelation between the mechanisms that operate in obesity to generate diverse respiratory entities and how to impact these mechanisms with therapeutic tools that allow prevent the appearance of these disorders. The vision that obesity is a multifactorial pathology where there are, environmental, genetic, immunological and inflammatory factors, is highlighted.
\end{abstract}

\section{Introduction}

Obesity is considered a greater health risk. It is defined, in the simplest way, as a condition characterized by an excessive accumulation and deposit of body fat. In 1997 the World Health Organization (WHO) formally recognized obesity as a global pandemic. In 2015 it was estimated that 107.7 million children and 603.7 million adults were obese worldwide. The overall prevalence of obesity was $5.0 \%$ in children under 20 years and $12.9 \%$ among adults, predominantly in women for all ages and higher in people over 50 years. Overweight accounted for approximately 4 million deaths and 120 million disability-adjusted lifeyears (DALY). $70 \%$ of deaths related to a high body mass index (BMI) were cardiovascular and $60 \%$ of these deaths occurred in obese people [1]. BMI (the index between body weight ([Kgs]/height [linear meters] to the second power) is the most practical, standard and widely used tool to define obesity. Obesity is quantified numerically when the BMI is $>30 \mathrm{~kg} / \mathrm{m}^{2}$. Among 25-30 is classified as overweight. In the United States (US) $40 \%$ of men and almost $30 \%$ of adult women are overweight and the prevalence of obesity is 36\% in the USA, $24 \%$ in Canada and $26 \%$ in the United Kingdom (UK). Mortality seems to be associated with elevated BMI as an independent risk factor in these countries [2]. $\mathrm{BMI}$ has become a risk factor for a group of chronic diseases in expansion that include cardiovascular, metabolic, musculoskeletal, neoplastic, psychological, renal, gallbladder and respiratory disorders [3-5].

Another significant fact is that not only has the prevalence of obesity increased in recent decades, but obesity also begins 10 years earlier than in previous, and therefore there is a longer period of induction of complications and mortality. Duration of 5-15 years of obesity doubles the risk of death from all causes, but greater than 15 years triples the risk. Duration of obesity is a risk factor for mortality and is independent of BMI [6]. The longer duration of obesity exposes the patient to greater endogenous production of toxic oxygen radicals (ROS), which damage DNA and enzymes that metabolize carcinogens and alter the metabolism of endogenous hormones [7]. There is a longer time to induce partial exhaustion of the $\beta$ cells of the pancreas, causing insulinopenia with depression of glucose oxidation and impaired glucose tolerance. This leads to hypertension, dyslipidemia, increased serum glucose, which increases the risk of chronic diseases such as diabetes mellitus, cardiovascular diseases and cancer [8].
The respiratory system does not escape this growing expansion of chronic diseases associated with obesity. This work tries to update the interrelation between obesity and more well-known pathologies like OSA, OHS and others of more recent description like the asthmatic phenotype associated with obesity.

\section{Obstructive Sleep Apnea (Osa)}

\section{Overview}

OSA is a pathology characterized by recurrent collapse of the pharynx during sleep, partially (hypopnea) or total (apnea), thus producing a decrease or absence of airflow despite the respiratory efforts of the patient [9]. The obstructive events (apneas and hypopneas) cause a progressive asphyxia, which as they increase, stimulate respiratory efforts against a collapsed airway, until the patient wakes up. These respiratory efforts related to awakening are known as RERA (respiratory event-related arousal). These episodes are associated with recurrent oxyhemoglobin desaturation [10]. OSA is the most common type of sleep-disordered breathing (SDB). OSA is commonly associated with excessive daytime sleepiness, which is why it is also called obstructive sleep apnea syndrome or obstructive sleep apnea-hypopnea syndrome (OSAH). The cardinal symptoms of OSA include the "3 S's": Snoring, Sleepiness and Significant-other of sleep apnea episodes. These mnemonics has proven to be of value in teaching. There really is a continuum from simple snoring to OSA and intermediate to upper airway resistance syndrome (UARS). (Figure 1). Some authors consider the term UARS obsolete considering that it is included in the category

*Correspondence to: Alcibey Alvarado, Clínica de Diagnóstico Médico, Torre Médica, 3 piso, Paseo Colón, San José, América Central, Costa Rica, Tel: 50622237134; 50622566439; 50687351858; Fax: 50622216754; E-mail: alcialvagonza@yahoo.com.mx

Key words: obesity, obstructive sleep apnea, obesity-hypoventilation syndrome, obesity-asthma phenotype

Received: August 23, 2018; Accepted: September 25, 2018; Published: September 28, 2018 


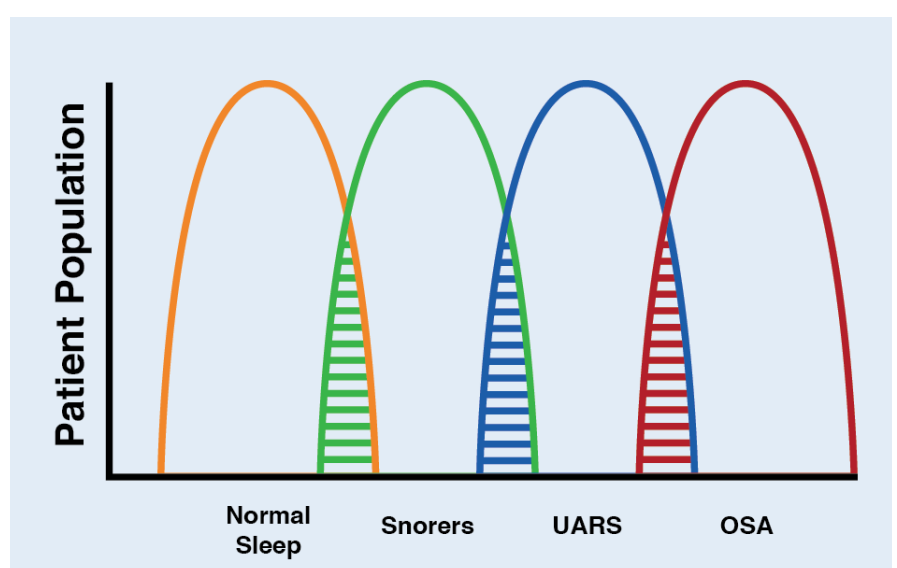

Figure 1. Interrelationship between SRDB and patient populations

Sleep-related disordered breathing continuum ranging from normal sleep to obstructive sleep apnea (OSA). Upper airway resistance syndrome (UARS) occupies an intermediate position between these extremes. Note areas of overlap among the conditions.

of OSA, but conceptually it is a valid term. This continuum is known as sleep-related breathing disorders (SRBD). The value of this concept is that simple snoring is seen as the beginning of the problem, which associated with others medical conditions can evolve to UARS and if it is not treated will evolve to OSA. Untreated OSA can lead to death through cardiac, metabolic, traffic accident and other complications.

The America Academy of Sleep Medicine (AASM) defines apnea as the cessation of airflow with duration of 10 or more seconds with respiratory efforts. Hypopnea requires a reduction of airflow of at least $30 \%$ with respect to basal flow and RERA is an event that is characterized by a respiratory effort of at least 10 seconds that leads to waking the patient but does not meet the criteria of apnea or hypopnea. The quantification of these events requires a study during sleep (polysomnography=PSG) [11].

\section{Epidemiology}

According to data from the Center for Diseases Control and Prevention (CDC) as early as 2013 the rate of sleep disorders reached epidemic proportions. In the US it affected 70 million people. It was estimated that 1 in 4 men and 1 in 10 women had OSA. This disease carries a high burden for society and health systems since it is associated with adverse events ranging from loss of productivity, increased risk of various diseases, to death [12]. The prevalence of SDB increases with age, and the prevalence of OSA also seem to be increasing. The data from the Wisconsin Cohort Study indicate that the prevalence of OSA in patients between $30-60$ years of age is $9-24 \%$ for men and $4-9 \%$ for women, increases with BMI and can reach $78 \%$ in patients with obesity morbid (BMI> 40) [13]. The prevalence in children is less accurate, but many authors who work with sleep have the perception that SDB are increasing in this population to how obesity has increased in adolescents and many have similarities with the counterpart of OSA in adults, with the important exception that they can be sleepy or hyperactive. One study estimated that approximately $6 \%$ of adolescents may have SDB [14].

\section{Clinical presentation}

Generally, OSA symptoms are insidious and are present for years before the patient is referred for an evaluation. Usually the patient presents with a history of loud snoring and involuntary movement during sleep, excessive daytime sleepiness, frequent awakenings during sleep, with feelings of breathlessness or gasping, decreased concentration and altered cognitive functions during the day [15]. Table 1 includes a list of nocturnal symptoms, Table 2 diurnal symptoms, Table 3 includes findings from the physical examination and Table 4 co-morbid conditions.

\section{Pathobiologic Features and Risk Factors}

The human upper airway is a unique structure with multiple purposes, involved in functions such as speech, mastication, swallowing solid and liquid foods and the passage of air. The anatomy and neural control of the upper airway has evolved to acquire these functions and is composed of 20 muscles and soft tissues but lacks rigid or bony support. Most notably, it contains a collapsible portion that extends from the hard palate to the larynx. Although the ability of the upper airway to temporarily change shape and momentarily close is essential for speech and swallowing during wakefulness, this feature also provides the opportunity for collapse at inopportunity times, such example as during sleep [16]. Multiple methods, including the cross-sectional area of the upper airway by computed tomography (CT) and magnetic resonance (MRI) have shown reduced caliber of this route in patients with OSA compared with controls in the waking state. However, there are non-anatomical factors of the upper airway that are crucial for the appearance of the disorder during sleep [17]. The transmural pressure is the difference between the pressure inside the airway (intraluminal

Table1. List of nocturnal symptoms

Nocturnal symptoms of OSA

Snoring, usually loud, habitual and bothersome to others

Witnesses apneas, which interrupt the snoring and end with a snort

Gasping and choking sensations the arouse the patient form sleep

Nocturia

Insomnia; with frequent arousals and involuntary movements during sleep

Table 2. Diurnal symptoms

Daytime symptoms of OSA

Nonrestorative sleep (the patient feels tired despite having "fallen asleep")

Morning headache, dry or sore throat

Excessive daytime sleepiness

Daytime fatigue

Cognitive deficit (intellect, memory, attention and execution)

Morning Confusion

Personality and mood changes (irritability, depression and anxiety)

Sexual dysfunction (impotence and decreased libido)

Table 3. Findings from the physical examination

\section{Physical examination in OSA}

Obese

Wide neck ( $>43 \mathrm{~cm}$ in men, and $>37 \mathrm{~cm}$ in women

Retrognathia or micrognathia

Crowded airway

Large tonsils

High-arched hard palate

Table 4. Co-morbid conditions

Co-morbid conditions in OSA

Resistant arterial hypertension

Recurrent arterial fibrillation

Stroke

Myocardial Infarction

Pulmonary hypertension

Chronic heart failure

Gastroesophageal reflux 
pressure) and the external pressure exerted by the tissues that surround it. The higher the transmural pressure, greater the opening of the airway. As the transmural pressure decreases, the opening is smaller. Once a critical point has been reached (Critical pressure=Pcrit) to reduce this pressure, a displacement of the pharyngeal tissues into the airway collapses (Figure 2). As long as the transmural pressure does not exceed this Pcrit, the airway will persist obstructed, perpetuating the event (apneas/hypopneas). Measuring the Pcrit is a well-established technique for quantifying the collapsibility of the upper airway during sleep [18]. On average, patients with OSA tend to have a critical pressure close to atmospheric pressure $\left(\mathrm{O} \mathrm{cm} \mathrm{H}_{2} \mathrm{O}\right.$ of water) during sleep, but there is considerable variability among patients with OSA. The range fluctuates between $-5 \mathrm{cmH}_{2} \mathrm{O}$ to $+5 \mathrm{cmH}_{2} \mathrm{O}$. A Pcrit equal to or close to $+5 \mathrm{cmH}_{2} \mathrm{O}$ indicates a highly collapsible airway, whereas if the Pcrit is sub-atmospheric it indicates a stable airway. The fact of keeping the upper airway dilated depends on the proper functioning of the dilator muscles. Among these, the most studied is the genioglossus muscle whose activity is diminished in patients with OSA [19]. It should be noted that the measurement of Pcri is invaluable in OSA research, but the clinical use is very limited because the protocols are technically changing, invasive (CPAP masks and catheters to measure pharyngeal pressure), they consume time and require trained personnel to collect and analyze data [17].

Anatomical factors such as enlarged tonsils, increased volume of the tongue, soft tissues or lateral walls of the pharynx (fat for example), increased soft palate length, abnormal positioning of the jaw or maxilla contribute to diminish the cross-sectional area of the upper airway and / or increase the pressure around it, which predispose to collapse [20]. In adults it is very rare that the enlarged tonsils and adenoids are the cause of OSA and in this age group removing them is also rarely an effective surgical remedy; in children, $80 \%$ of those who have OSA heal with the removal of them [21].

Two non-anatomical factors are fundamental for the appearance of OSA; the reduced neuromuscular response of the upper airway to the central impulses and the instability of the central control. Neuromuscular activity of the upper airway, including reflex activity,

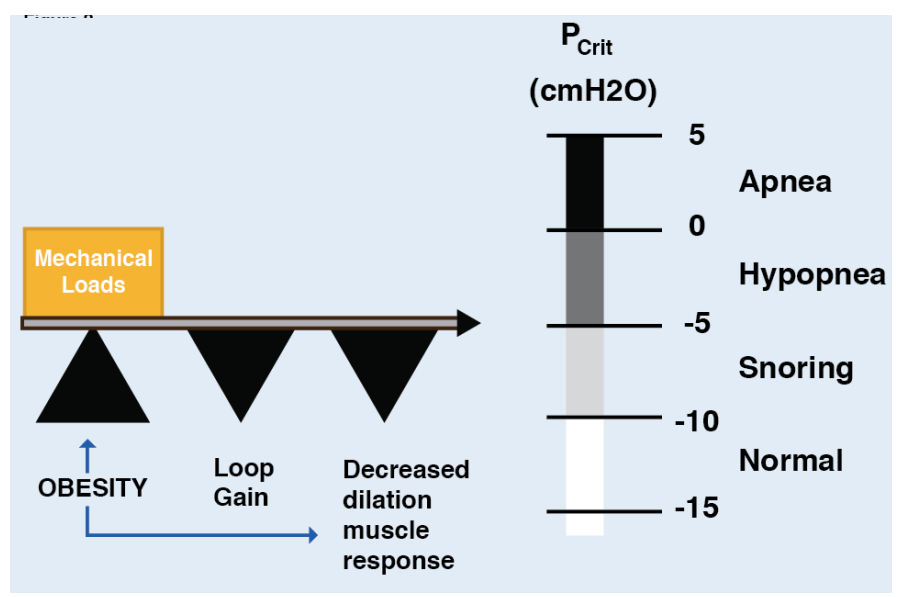

Figure 2. Pcrit pivot role in pathogenesis of OSA

Upper airway collapsibility during sleep is represented by the critical pressure (Pcrit), which spans a range from health (negative) to disease (positive). Pcrit is determined by the mechanical loads imposed by boney structures and soft tissues on the pharynx, and are offset by neuromuscular responses to airway obstruction. Obesity can influence passive mechanical loads and neuromuscular control, thereby modulating upper airway collapsibility and sleep apnea susceptibility. The diminished central ventilatory stimuli contribute to this event decreases during sleep, and this reduction may be more marked in patients with OSA [22]. This reduced response of the dilator muscles (which should be activated during sleep when the airway tends to collapse) is critical for initiating obstruction, particularly if there are anatomical reasons predisposing to collapse [23]. For example, the genioglossus muscle receives central impulses from the brainstem but also reflex impulses of pharyngeal mechanoreceptors (basically negative pressure, sub-atmospheric or intra-luminal suction) and chemoreceptors. The loss of this reflex control contributes to the pathogenesis of OSA [24]. An increased reflex response could protect obese individuals from the development of OSA, despite the anatomical compromise [23]. Basically the dilator muscles must be activated and contracted to oppose the sub-atmospheric suction pressure in the pharynx during sleep and avoid collapse.

Instability of central control has also been described in patients with OSA during sleep. That is, in addition to an altered sensitivity and reduced activity of the dilator muscles of the upper airway, there is a reduction in ventilatory motor impulses during sleep. In fact, a mismatch has been described between the central neuronal impulses (loop gain) and the response of the dilator muscles [24]. Thus, the combination of anatomical and non-anatomical compromise is crucial in preventing or promoting OSA. Another significant association is that between lung volume and permeability of the upper airway. When the pulmonary volume is reduced, there is a displacement of the diaphragm and thorax cephalad, which results in a loss of caudal traction in the upper airway favoring collapse [25].

In addition to structural and non-structural factors, in OSA a substantial degree of genetic control interacts with environmental factors. There is familial aggregation and racial predisposition that contribute to the development of the syndrome and the structural phenotype of the upper airway [26]. Soft tissue traits of the upper airway, abnormalities of ventilatory control, respiratory response to resistive loading during sleep may have a genetic basis [27-30]. Studies of candidate genes have found in European Americans that C-reactive protein (CRP) and glial cell line-derived neutrophilic factor (GDNF) were associated with $\mathrm{AHI}$ as dichotomous and longitudinal trait and in African Americans variants of the 2A serotonin receptor. CRP seems to mediate inflammation in OSA. GDNF influences ventilatory control because it senses oxygen and $\mathrm{CO}_{2}$ in the transition to sleep, the response to hypoxia of the carotid body and the A5 nucleus of the ventrolateral pons, a critical area that regulates the generation of the respiratory pattern [31].

In OSA, oxidative stress and inflammation have been correlated. A gene encoding oxidative stress contributing to OSA has even been described. The gene could play a pivotal role by operating in a positive feedback loop causing OSA to begin with and then triggering an inflammatory response that obstructs the upper airway, exacerbating OSA [32]. Metabolic syndrome is characterized by fasting hyperglycemia, systemic hypertension, dyslipidemia and obesity. There is evidence of oxidative stress and pro-inflammatory activity in this syndrome and also that OSA can contribute to its metabolic damage (Figure 3). Multiple studies have shown that patients with OSA have hyperglycemia of fasting and insulin resistance [33].

To the extent that fat accumulates in fat reserves, adipokines (cytokines, chemokines, complement proteins and other acute phase reactants, plasminogen activator inhibitor I, eotaxin, VEGF and MCPI produced by adipose tissue) are secreted and released into the blood by influencing the function of the upper airway during sleep and exercising its pro-inflammatory activity. These factors regulate the distribution of 


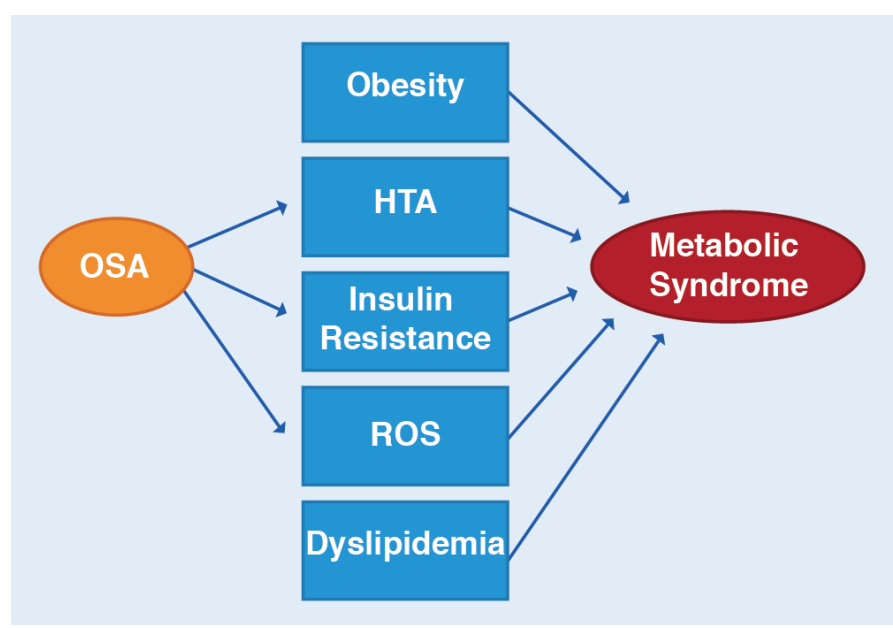

Figure 3. Relationship between OSA and the metabolic syndrome

OSA has been associated with 3 of the 5 major clinical abnormalities associated with the metabolic syndrome, which is hypertension, insulin resistance, and oxidative stress. OSA may be contributing to and/or modulating the severity of these metabolic abnormalities

body fat between the central (visceral) and peripheral (subcutaneous) compartments. Hypoxia of adipose tissue stimulates the infiltration of fat with macrophages that also release inflammatory mediators. Leptin and adiponectin are energy-regulating hormones [34]. Leptin is a hormone that has to do with satiety, is elevated in obese patients and promotes inflammation. Adiponectin is an insulin-sensitizing hormone, has anti-inflammatory effects and is decreased in obese, favoring insulin resistance and inflammation. Obesity can induce an inflammatory state since adipose tissue is a source of pro-inflammatory cytokines such as TNF- $\alpha$, IL-6, IL-18, IL-1B and leptin antagonists (SOBR $=$ soluble leptin receptor) and PCR $[35,36]$. The fundamental point is to understand that obesity, OSA and metabolic syndrome have in common denominator an inflammatory phenomenon [37].

Two other events that have pathophysiological and therapeutic importance are apnea clusters and the respiratory threshold to arousal. Apneas during sleep occur in clusters and desaturation of hemoglobin occurs after each apnea, but is more marked after the first apnea than in the rest of the cluster. CPAP and oxygen together reduce desaturation to the extent that apneas may remain isolated [38]. Awakening is not an essential event, as originally believed, for the reopening of the airway. There are patients with low threshold to wake up and others with high threshold. Frequent awakenings fragment sleep, which becomes unstable and prevents access to deep stages. Theoretically, strategies that reduce awakenings could allow a more stable breathing during sleep, reduce fragmented sleep and make it more restorative [39]. For patients with the low threshold phenotype, the use of hypnotics is a common area of research. The patient and the drug must be exquisitely selected to increase the threshold but not reduce the activity of the respiratory muscles [40]. However, in patients with high respiratory threshold for awakening, they are in danger, with hypnotics, of deepening and prolonging hypoxemia due to a dull breathing.

In addition to obesity, which is an obvious risk factor for OSA (but not all patients with OSA are obese) [41], there are two non-genetic risk factors: male gender and age. In the male gender OSA is more frequent than in the female gender, in a ratio of 2-3: 1 [42]. Possibly this is due to the distribution of fat, as in the male gender there is a greater deposit of fat around the pharyngeal airway, and greater length of it which predisposes to collapse. Hormonal factors have also been invoked because the administration of testosterone in men with hypogonadism induces SDB. Post-menopausal women have OSA most frequently than pre-menopausal women [43]. Women with hormone replacement therapy have a similar prevalence to pre-menopausal women. OSA is more frequent in patients older than 65 years. Greater deposition of fat and deterioration of the activity of the dilator muscles of the pharynx with age have been invoked as underlying mechanisms [44].

OSA is more frequent in the REM (rapid-eyes movements) phase of sleep than in the non-REM phase. The REM phase is associated with a decrease in the tone of the muscles of the upper airway, altering the ability of the dilator muscles (for example, the genioglossus) to exert a negative pressure outside the airway that pulls it, and also reducing the sensitivity of chemoreceptors. The relevance of surface tension of the upper airway in OSA and the impact of mechanical trauma and hypoxemia on prolonging and perpetuating the severity of OSA is not clearly known [16].

\section{Diagnosis}

As early as 2014, the American College of Physicians recommended that every patient with daytime sleepiness should undergo a sleep study, preferably a PSG. The modalities available to identify the site of the obstruction include: lateral cephalometry, endoscopy, fluoroscopy, CT, MRI, and radiography. The respiratory function tests are not indicated for diagnosis or for the treatment plan in OSA alone. They may be indicated for patients with OSA who have co-morbid conditions that require testing. Routine laboratory studies at OSA are not helpful unless there are specific indications. Thyrotropin should be quantified if hypothyroidism is suspected. Cysteine has been described as a marker of OSA [45].

PSG is necessary for accurate diagnosis and evaluation of treatment. It must be done in a sleep laboratory accredited by the AASM, because it requires qualified technicians to attend the monitoring and specialized doctors to interpret the study. The stages of sleep are recorded by means of an EEG, electro-oculogram and an electromyogram (EMG) of the chin. The heart rate is monitored with a single-derivative EKG. Limb movements of the legs are collected via an anterior tibial EMG. Respiratory monitoring includes airflow of the nose and mouth (using thermal sensors and nasal pressure transducers), respiratory effort (using inductance plethysmography) and oxygen saturation of hemoglobin (pulse oximetry). Esophageal pressure monitoring was not performed in many sleep laboratories due to the invasive nature of the procedure. It serves to measure, indirectly, the resistance of the airway (UARS). The respiratory pattern is analyzed according to the definitions standardized by the AASM [46]. Obstructive apnea is the cessation of airflow of at least 10 seconds with persistent respiratory efforts. Central apnea is the cessation of airflow of at least 10 seconds without respiratory efforts. A mixed apnea is an apnea that starts as a central apnea and ends as an obstructive apnea. The apnea-hypopnea index (AHI) is derived from the total number of apneas and hypopneas divided by the total sleep time. The normal value is controversial and many laboratories use about 5 events per hour. Arbitrarily the severity is a function of the number per hour. There of 5-15 mild, of 15-30 moderate and greater than 30 , severe. Not necessarily the highest HAI correlates with the greater hypoxemia [47]. RDI (respiratory disorders index) is an index that is sometimes used for decision making and refers to the number of events (they are not necessarily just apnea or hypopnea) that limit air flow and end in awakenings. It is not the same as there.

Patients with an RDI greater than 40 during the first $2 \mathrm{~h}$ of a PSG qualify at that time for a Split-night PSG, in which, the final phase of the 
study is used to titrate the continuous positive airway pressure and does not require a second conventional PSG to calibrate the CPAP device. In other words, the study is done and the CPAP is titrated in a single time. Diagnosis and treatment are made. If the RDI is $20-40$, it can be considered Split-night PSG if the clinical observation shows prolonged obstructive events or marked desaturation of the oxygenation. A minimum of 3 hours of sleep is required to the titrated of the CPAP once the treatment with the same begins. If a single Split-night study does not allow adequate control of symptoms, a full-night CPAP titration is necessary [46]. Repeat PSG is necessary if symptoms are not controlled with CPAP despite adequate adherence, to evaluate response to upper airway surgery, evaluate response to oral application therapy (OA), if a $15 \%$ increase occurs of previous weight and to assess the response to a REM suppressant medication if the symptoms persist.

Considerable controversy exists about the validity of the studies conducted with portable equipment in the home compared with those carried out in a sleep center with a PSG. From the available information, it is worth highlighting several facts. Home studies are not inferior to a PSG for the OSA study if the pre-test probability is high for OSA. Home studies do not measure sleep and therefore may underestimate the degree of apneas, leading to false negatives, particularly in patients with insomnia, or other coexisting sleep disorders, or with medical conditions that contraindicate the study (heart failure). However, if the results with the portable equipment are negative, the conventional PSG must be done [48]. A new disposable patch placed on skin has been developed to detect apneas, with promising results $[49,50]$.

A frequently used clinical diagnostic scale is STOP-BANG consisting of 8 data with yes or no answers $(\mathrm{S}=$ snoring, $\mathrm{T}=$ tired/ sleepiness, $\mathrm{O}=$ observed apneas, $\mathrm{P}=$ arterial hypertension, $\mathrm{B}=\mathrm{BMI}>25$ $\mathrm{Kg} / \mathrm{m}^{2}, \mathrm{~A}=$ age, $\mathrm{N}=$ neck width $>40 \mathrm{~cm}, \mathrm{G}=$ male gender). With a $0-2$ score, moderate to severe apneas can be excluded. A score of 3 or more suggests apneas. The positive predictive value is low (31-47\%) with a high rate of false positives. The sensitivity ranges from $92.9 \%$ (slight apneas) to $100 \%$ (severe apneas). It basically works to evaluate the severity of the apnea and define the need for a PSG [51].

\section{Non-pharmacological management}

The objectives of OSA treatment are basically two: to eliminate apneas and eliminate intermittent hypoxia and the complications that arise from it. As general measures it is recommended to sleep in lateral decubitus and although several positional therapies (PT) have been proposed, none is really superior to the others, the results are inferior to CPAP and the impact on the metabolic and / or cognitive component of the entity are unknown [10]. You should not drink alcoholic beverages 4-6 hours before bedtime, and you should lose weight. A reduction of $10 \%$ of the weight leads to a reduction of $26 \%$ of RDI. The benefits of losing weight are several such as: lowering blood pressure, improving lung function and arterial blood gases, improving sleep structure, reducing snoring, awakening, and the level of optimal CPAP. The suspension of smoking and psychotropic drugs not prescribed by a professional should be encouraged.

The treatment of SRBD with CPAP first corrects OSA, then UARS, and finally snoring, and if the therapy is stopped prematurely, the symptoms recur. A problem with CPAP is that the adherence is unacceptably low [52]. Although it is standard therapy and reduces morbidity and mortality, adherence is crucial not only for the management of OSA but also for other co-morbid conditions or complications. There are more than 100 CPAP masks to personalize the device but the chosen CPAP should cover nose (n CPAP) or nose- mouth (total-face CPAP) [13]. Nasal CPAP is effective in OSA, mixed apneas and in some central apneas. It is a fan unit, which produces a positive pressure, of nasal application, which increases the caliber of the airway in the retro-palatine region and retro-gloss regions, acting as a pneumatic splint. The pressure applied to the airway must be higher than the Pcrit to avoid the collapse of the upper airway it must abolish the apneas / hypopneas, the desaturation of the hemoglobin, the snoring and the RERAs. The usual pressure ranges from 5-20 $\mathrm{cm} \mathrm{H}_{2} \mathrm{O}[53,54]$.

Other potential benefits of CPAP are improvement in daytime sleepiness, high blood pressure, risk of stroke, heart disease (has positive effects on cardiac remodeling), and metabolic syndrome [55]. It does not seem to have an effect on cognitive function. It also reduces costs and mortality [47]. The improvement can be immediate or take up to 2 months to be noticed. If CPAP is discontinued early, restlessness and other OSA markers are reinitiated, usually in the first two weeks. Since the acceptance is poor (25\% do not use it as indicated) [56], the equipment allows to monitor not only "the time in the machine" but "the time in the mask". It is recommended at least 4 hours/night/5-7 days although this recommendation is variable. The ideal is at least 7 hours per night and the tolerance of the first 3 months is critical for the continued use of CPAP. Education at various levels improves adherence. The experience of the technical team, and the close, regular and persistent follow-up, increase the use of the equipment. The complications that favor abandonment come from airflow and pressure. Suffocation, claustrophobia, difficulty in exhaling and sleeping, chest and musculoskeletal discomfort, aerophagia and sinus congestion are some the complaints. Less frequent are the pneumomediastinum, pneumothorax, pneumocephalus, tympanic rupture, skin abrasion, rash, conjunctivitis and nasal discomfort.

BIPAP is a modality that allows the inspiratory pressure of the expiratory to be adjusted independently. Also known as BILEVEL, positive expiratory pressure levels are adjusted to eliminate apneas and positive inspiratory pressure to eliminate hypopneas. The independent adjustment allows a decrease in airway pressure during the cycle, unlike conventional CPAP in which the pressure is continuous throughout the cycle. Therefore, the main indication is for patients who do not tolerate CPAP with high levels of pressure, patients with hypoventilation syndromes or associated COPD. It is much more expensive and has no clear advantages compared to conventional CPAP and neither is adherence much better [57]. The technical improvements in equipment of last generation are evident. They weigh around $1.4 \mathrm{~kg}(3 \mathrm{lbs})$ and generate less than $4 \mathrm{~dB}$ of noise, which is less than that generated during a quiet conversation. The AASM suggests using BIPAP when the CPAP pressure exceeds $15 \mathrm{cmH}_{2} \mathrm{O}$ [53]. Automatic adjustment of the positive airway pressure (APAP), using an appropriate algorithm, can automatically increase or decrease the pressure based on the respiratory events identified. It is of particular help in patients who require the machine in the supine position rather than in the non-supine position and for patients with residual apneas greater than 10 /hour after bariatric surgery [58]. The short-term prognosis with positive pressure is good in many variables. The long-term prognosis is not known.

Oral application devices (OA) move the tongue forward or move the jaw and soft palate anteriorly, lengthening the posterior air space and dilating the airway. The minimum protrusion needed to be effective is $6-10 \mathrm{~mm}$, and there are 3 basic designs with more than 40 devices on the market. The most used are MAS (mandibular advanced splint) and TRD (tongue-retaining devices) [10]. AASM has published practical parameters and review of the use of OA in OSA [59]. Basically $\mathrm{OA}$ is recommended in patients with mild-moderate OSA who do not 
tolerate CPAP or BIPAP. There is little benefit in severe OSA. It requires evaluation by a sleep specialist and a dental professional and a PSG that confirms efficacy. The goal is to reduce AHI to $<5 /$ hour, eliminate snoring and improve the sleep architecture. The ideal candidate is the patient with low BMI, young, with a small neck circumference, with normal pharynx and with positional OSA. CPAP is more effective than OA in reducing AHI by 5-10/hour. The adherence is not well defined but it seems to be low. Problems with the temporomandibular joint (occlusive changes), excessive salivation, discomfort in the face, misalignment and dental displacement, changes in the bite, myofascial pain, chewing sounds and tongue pain are some of the causes of inefficiency and no adhesion [60]. The price of equipment ranges from $\$ 300-2,500$.

Electrical stimuli of the upper airway applied through an electrode that is implanted in the hypoglossal nerve and a device that is implanted in the skin of the thorax have been proposed for patients who can't tolerate CPAP. Although it is true that some indicators of upper airway obstruction such as AHI, sleep structure, hypoxemia and the Epworth scale can improved [61] and Woodson and colleagues have shown efficacy and subjective benefit at 18 months of their use [62], its longterm benefits are not clear and a third of patients do not respond [63]. Provent ${ }^{R}$ is a one-way valve that maintains a constant pressure in the pharynx, without requiring tube or electricity [13].

Surgical treatment in OSA is defined in two levels: surgery for weight reduction and upper airway surgery. Obesity is a major risk factor for OSA and 70\% of patients with OSA are obese, and there is a well-documented correlation between BMI and AHI, therefore all patients should be encouraged to lose weight [64]. Unfortunately many diet programs to lose weight fail, because other OSA determines metabolic changes that prevent weight loss. In patients with severe obesity (BMI $>40$ ), bariatric surgery, including gastric bypass and bandage, is a modality of weight reduction when the conventional method fails [65]. Both alternatives may have beneficial effects in OSA, although the surgical alternative offers a greater and significant improvement over the non-surgical one [66].

The role of surgery in upper airway management in OSA remains extremely controversial and the reason why it is not a standard approach is the absence of long-term studies that show that it continues to be effective 5 years or more after it has been performed. The goal of the surgery is to remove the cause of the obstruction and expand the airway [10]. The most frequent sites of obstruction are the oropharyngeal tract (collapse of retro-gloss and retro-palatine regions due to macroglossia, low soft palate, or enlarged tonsils) and the nose (congestion, polyposis, and chronic rhinitis) [67]. Nor should it be conceptualized as a "last ditch" attempt since it may be the correct alternative if OSA is minimal $(\mathrm{RDI}<20)$ and oxygen saturation of hemoglobin $>90 \%$, medical therapy is rejected and the patient is stable for a surgical procedure, or if CPAP fails, or if there are specific abnormalities that cause OSA ( 3 of 200 patients with OSA have space-occupying lesions that cause the obstruction). Many patients have non-correctable space-occupying injuries [68].

Obstruction in patients with SDB is classified anatomically into 3 types according to the region involved. Type I only involves the retro-palatine region, III the retro-gloss region and II both. Uvulopalatopharyngoplasty (UPPP) corrects type I obstruction. UPPP resects the uvula, soft palate, tonsils and redundant pharyngeal tissue. It is effective only in $40 \%$ of patients and the symptoms recur if the patient gains weight. In addition, side effects appear in $20-30 \%$ of patients (veilpalatal insufficiency, dry throat and problems with swallowing). The genioglossus advancement with hyoid myotomy (GAHM) can correct the type III obstruction and the maxillomandibular osteotomy (MMO) corrects the obstruction at both levels. There are really no good studies that evaluate the success of craniofacial reconstructions. In adults, the nose infrequently has an impact on sleep apnea [69]. Tonsillectomy and adenoidectomy are the surgical procedures to treat OSA in children and are highly effective [21]. The UPPP can be conventional or assisted with lasser (LAPP). Radiofrequency ablation of the palate (RFA) is a less invasive alternative than UPPP and consists of generating a scar on the soft palate to generate stiffness [70]. But again, there is an absence of good evidence of effectiveness. The fundamental problem with these procedures is that the effectiveness decreases with age and weight gain and this is a determining factor in the recurrence of OSA after surgery.

Tracheostomy provides definitive correction because "bypasses" the obstruction. It is indicated for severe OSA that does not tolerate CPAP or that has cor-pulmonale. It is $100 \%$ effective, but it is disfiguring and drastically decreases the quality of life.

The application of negative oral pressure as an alternative to positive pressure awaits future research into a technology that is evolving.

\section{Pharmacological management}

To date, pharmacological attempts to increase upper airway activity have not been particularly successful and are not recommended as primary OSA therapy [71,72]. The antidepressant, desipramine, can reduce the collapsibility of the upper airway, increasing the response of pharyngeal muscles to obstruction during sleep [73]. The hypnotic Zolpidem (acts on the adrenergic GABA system) also increases the response of the pharyngeal muscles during sleep [74]. Residual somnolence despite effective treatment with CPAP occurs at $5 \%$. Sometimes because with the initial improvement there is a tendency to underutilize CPAP a posteriori, alcohol use, changes in medication or use of sildenafil. It should be remembered that the latter inhibits cGMP phosphodiesterase by prolonging the action of cGMP and NO which promotes congestion of the upper airway, muscle relaxation and pulmonary vasodilation exacerbating OSA [75]. If a clear cause of the phenomenon is not found and the level of CPAP is optimal, modafinil or armodafinil (approved by the FDA for this indication) can be added at a dose of $100-200 \mathrm{mg}$ VO for fatigue or $400 \mathrm{mg}$ to induce sleep [76]. Acetazolamide, medroxyprogesterone, fluoxetine, protriptyline, metil-xanthines and estrogens are not recommended. In the pediatric population, subjected to tonsillectomy due to OSA, opioids should be used with care, preferring acetaminophen / ibuprofen as analgesics in the postoperative period [61].

To summarize the treatment, to all patients should be offered CPAP. If OSA is minimal-moderate and rejects n CPAP, BIPAP can be offered. If it fails or is rejected, it can be turned to OA. OA could be considered primary therapy if OSA is minimal and rejects CPAP. All available tools should be used to induce use and improve CPAP tolerance. The use of surgery or pharmacological treatment should be left to a sleep disorder specialist and a center with experience in the procedures.

\section{Complications and mortality}

OSA severe, untreated, has a higher risk of cardiovascular mortality, basically myocardial infarction and stroke, and although controversial, the risk seems to be reduced with the use of CPAP [77-79]. Patients with OSA have twice the prevalence of coronary artery disease and 2-4 times more risk of complex arrhythmias (bradyarrhythmias, AV block, premature ventricular contractions) and atrial fibrillation [80]. The risk of atherosclerosis increases with OSA by exacerbating atherogenic 
factors such as systemic hypertension, insulin resistance, diabetes mellitus, dyslipidemia, and systemic inflammation. CPAP can attenuate this effect [81]. CPAP reduces the activity of the renin-angiotensin system associated with decreased glomerular filtration and increased renal plasma flow, reduces plasma aldosterone and proteinuria. The connection between OSA and chronic kidney disease is generated by hyperfiltration induced by hypoxia [61]. The Sleep Hearth Health Study showed that OSA has a strong association with stroke, greater than any other cardiovascular disease [82]. Repeated acute cardiovascular stress due to occlusion of the upper airway generates hypoxemia, re-oxygenation (ROS), cyclic changes in intrathoracic pressure, and fragmented sleep. All these mechanisms are responsible for hypertension of the pulmonary artery in OSA [83].

OSA is associated with an increase of 2.5 times the risk of traffic accidents [84].

COPD affects $10 \%$ of the adult population, older than 40 years. SAHS affects $5 \%$ of the same population. The coexistence of both occurs at $0.25 \%$ and is known as overlap syndrome. Actually the prevalence of SAHS is not higher in patients with COPD than in the general population and the occurrence of both is a statistical association but there is no pathophysiological connection between the two entities. In this type of patients, dyspnea is greater than expected for the degree of bronchial obstruction, its functional compromise is greater and the optimized treatment of both pathologies improves survival [85]. Patients with childhood onset asthma have an increased risk of subsequent OSA. The risk is double in this population with respect to asthma starting in adult life [86]. OSA has been described associated with idiopathic pulmonary fibrosis [87].

OSA and epilepsy are particularly associated in older adults with recent-onset epilepsy, and seizure control improves with treatment, not only anticonvulsants, but also co-existing OSA [88]. Studies in animals and "in vitro" have shown that intermittent and chronic hypoxia promotes tumor growth and resistance to radiotherapy. The data analysis of the Wisconsin Sleep Cohort Study demonstrated an association between cancer mortality and severity of OSA and hypoxemia. The association between tissue hypoxia and cancer can be explained by the increased hypoxia-induced angiogenesis since the activation of inducible hypoxia factor (HIF-1 $\alpha$ ) stimulates vascular endothelial growth factor (VEGF) in tumor cells [89].

\section{Obesity Hypoventilation Syndrome (Ohs)}

\section{Introduction}

Alveolar hypoventilation can be caused by several disorders that are collectively classified as hypoventilation syndromes. Patients with alveolar hypoventilation have ventilatory failure leading to hypercapnia, that is, an increase in $\mathrm{pCO}_{2}$. They can also develop hypoxemia that aggravates clinical manifestations. Causes of alveolar hypoventilation include: central alveolar hypoventilation, deformities of the chest wall, neuromuscular disorders, COPD and OHS which is the subject that is discussed below [90].

\section{Etiology}

Patients with OHS have abnormal ventilatory control and obesity, both contributing to the development of the syndrome. It is defined as such, the combination of obesity $\left(\mathrm{BMI}>30 \mathrm{Kg} / \mathrm{m}^{2}\right)$ and chronic hypercapnia $\left(\mathrm{pCO}_{2}>45 \mathrm{~mm} \mathrm{Hg}\right.$ or $\left.>5.98 \mathrm{Kp}\right)$ in absence of other pathologies that cause hypoventilation (neuromuscular, metabolic, pulmonary or chest wall). $90 \%$ of patients with OHS have OSA [91].
This hypoventilation worsens during REM as does OSA. These patients have a high incidence of restrictive disorders in pulmonary function tests, excessive respiratory work, increased $\mathrm{CO}_{2}$ production and reduced pulmonary compliance when compared with obese patients without the syndrome [92]. Leptin deficiency or resistance to it can contribute because the deficit of the hormone reduces the ventilatory response and promotes $\mathrm{CO}_{2}$ retention. Obese mice, genetically altered, with leptin deficiency are phenotypically similar to patients with OHS. The replacement of leptin in mice reverses chronic hypercapnia suggesting a possible role in the pathogenesis of OHS. The most important factor for the onset of the syndrome is an effect on central respiratory control with a reduced response to hypercapnia, hypoxia or both [93].

\section{Epidemiology}

The prevalence of OHS in the adult population rangers between $0.15-0.30 \%$ [94]. Data from the CDC show that with the increase in obesity the prevalence of OHS will increase [95]. It is more common in men than in women in a ratio of 2:1 and usually in people older than 50 years [96]. HTAP is more common and more severe in patients with OHS than with OSA alone and patients with OHS have higher admission rates in CCU than obese patients without hypoventilation [91].

\section{Clinical evaluation}

The clinical manifestations of hypoventilation syndromes are nonspecific, and depend mainly on hypoventilation and the development of hypercapnia and hypoxemia. At the beginning, patients are asymptomatic or with minimal symptoms, such as dyspnea of exercise and as it progresses, cyanosis, delirium, confusion, drowsiness and obtundation due to hypoxemia and $\mathrm{CO}_{2}$ narcosis appear. Asterixis, myoclonus, seizures and papilledema may appear, as well as dilation of facial and conjunctival vessels [97]. Patients with OHS may have OSA symptoms such as hyper-drowsiness, fatigue, loud snoring, nighttime asphyxia, and morning headaches. They may also have pulmonary hypertension with right heart failure and peripheral edema in advanced disease (Pickwickian syndrome). At the physical examination, in addition to the obvious obesity, cor-pulmonale data will appear. Arterial gases to evaluate hypoxemia and acid-base status, blood count (polycythemia), EKG (right ventricular hypertrophy and right atrial growth), chest x-ray (heart failure), echocardiogram (pulmonary artery pressure and right ventricular growth) and respiratory function tests (document restriction severity) are part of the diagnostic work in OHS. The total percentage of sleep with $\mathrm{SpO}_{2}<90 \%$ can be a polysomnographic variable of help to evaluate patients with OHS [98].

\section{Treatment/Management}

OHS is associated with a high rate of morbidity and mortality. The goal of management is to normalize $\mathrm{pCO}_{2}$, reduce the desaturation of oxyhemoglobin and improve symptoms. Non-invasive positive airway pressure therapy is typically the first-line treatment for OHS [99]. This modality significantly reduces the nocturnal $\mathrm{pCO}_{2}$ increase and improvers sleepiness during the daytime. The alternatives for this modality are CPAP, BiPAP and other NIV modalities (non-invasive ventilation). CPAP is recommended if SRBD coexists and NIV if the patient has hypercapnia in the absence of apneas or hypopneas. BiPAP is the choice if there is nocturnal desaturation of oxyhemoglobin or nocturnal increase in $\mathrm{pCO}_{2}$. NIV and CPAP significantly improve the polysomnographic and respiratory parameters compared with other modalities such as lifestyle modification [100]. 50\% of patients with OHS, with positive pressure, also require oxygen therapy. Only oxygen 
for OHS is an inadequate strategy. Weight loss significantly improves OHS symptoms by reducing $\mathrm{CO}_{2}$ production, the severity of sleep apnea and alveolar ventilation. It also reduces pulmonary hypertension and left ventricular dysfunction, which improves cardiovascular compromise in OHS. The fundamental problem in the modern world is to keep the weight stable. Bariatric surgery with its different alternatives (produce gastric restriction or malabsorption) should be considered for refractory cases since operative mortality is high in OHS. Tracheostomy relieves airway obstruction during sleep, improves alveolar ventilation and $\mathrm{pCO}_{2}$ during wakefulness, but some patients do not return to the eucapnic state and do not change $\mathrm{CO}_{2}$ production. Sodium bicarbonate should not be infused because the central nervous system is alkalinized, which can cause seizures and the consequent metabolic alkalemia can generate cardiac dysrhythmias. Acetazolamide and medroxyprogesterone can potentially reverse hypercapnia but its routine use is not recommended due to the narrow margin between safety and long-term side effects. Leptin replacement therapy has shown relief of nocturnal hypoventilation and obstruction of the airway during sleep secondary to increased upper airway respiratory stimulus and diaphragm in experimental studies with mice, but its use in humans is not recommended [101].

\section{Prognosis}

OHS is associated with reduced quality of life and prolonged admission and time rates in intensive care units. In patients with associated comorbidities such as diabetes mellitus and bronchial asthma, mortality is significantly high, greater than $23 \%$ at 18 months and $46 \%$ at 50 months. Early use of CPAP can reduce the associated mortality to $10 \%[99,100]$.

\section{Asthma and Obesity}

Bronchial asthma is the most common chronic inflammatory disease in children and adults. It affects approximately 315 million people in the world, with a prevalence of $1-16 \%$ and it is estimated that it causes 346,000 deaths each year [102].

The prevalence of asthma is increasing in obese patients, particularly in women with abdominal obesity $[103,104]$. Weight reduction may decrease the incidence of asthma. There is, with weight reduction, an improvement in lung function and symptoms, but not of obstruction or bronchial hyperreactivity.

Patients with severe asthma constitute $3-10 \%$ of the asthmatic population in adults with asthma, but consume more than $60 \%$ of the costs of the disease, basically by medication. These costs are higher than the costs for diabetes mellitus type 2, stroke and COPD [105]. From the point of view of inflammatory profile, there are two asthmatic phenotypes. In persistent type 2 inflammation, patients produce Th2 cytokines (IL-4, IL-5, IL-13) which promote the production of $\operatorname{IgE}$ and eosinophils. In the paucigranulocytic inflammatory pattern there is little inflammation of the airways and bronchial obstruction presumably occurs by other mechanisms. Within the first phenotype there is a cluster of obese patients. Moore and colleagues have identified several clinical phenotypes within the group of severe asthmatics. The phenotype associated with obesity (type 3 ) is characterized by being mainly older women, obese, with late onset asthma, with moderate reduction in FEV1 and frequent use of health resources, which require oral steroids for the management of exacerbations and with eosinophilic airway inflammation [106]. Generally, the obstruction is mild compared to symptoms that are disproportionate to the alteration of lung function. Persistent eosinophilia of airways while receiving high doses of inhaled steroids suggests insensitivity to steroids and/ or systemic effects of obesity [107]. From the perspective of childhood asthma the relationship with obesity had not been clear either. Chen and colleagues found in their work that early-onset asthma increases the risk of obesity in children. Interestingly, the use of rescue bronchodilators (and no other medication) reduced the risk by half [108]. $\mathrm{B}_{2}$-agonists can protect against obesity since fat cells have receptors for $\beta$-agonists and their stimulation produces lipolysis [109].

The information in the literature allows postulate several mechanisms or points of union between asthma and obesity. Obesity increases the prevalence of asthma and reduces control. In obesity the tidal volume and the residual functional capacity are diminished, which promotes airway obstruction. Obesity induces a low-grade inflammatory state that can impact the airway to exacerbate asthma. Changes in hormones derived from adipose tissue such as leptin and adiponectin can participate in these events. Comorbidities associated with obesity such as dyslipidemia, GERD, SDB. DM or HTA can make asthma worse $[110,111]$. Genetic, hormonal and neurogenic influences have also been invoked [104].

\section{Conclusions}

Obesity is a current pest in which genetic, racial and possibly other factors are involved, but the environmental factor is the main one due to the bad eating habits of the modern world.

With few exceptions, no population of the planet escapes its impact.

This pathology has a deep metabolic, immunological and inflammatory background disorder that encompasses various organs and systems of the human economy ranging from cardiovascular diseases to cancer.

The respiratory system does not escape this expanding spectrum of various diseases and includes OSA, OHS, overlap syndrome between COPD and OSA, and asthma associated with obesity.

Although it is true that each of them has an associated pathogenic component such as inadequate central ventilatory control, or imbalances between the central impulses and the response of muscles of the upper airway, or an inflammatory profile of their own, obesity is a determining factor in the expression of syndromes

Therefore, although the investigations of the alternative pathogenic mechanisms are important, research in obesity and particularly in prevention is vital, since to the extent that weight control is achieved, the health intervention of the various diseases associated with obesity, can be reduced and better controlled by decreasing morbidity and mortality rates and the costs of health systems.

\section{References}

1. GBD (2015) Obesity Collaborators, Afshin A, Forouzanfar MH, Reitsma MB, Sur P, et al. (2017) Health Effects of Overweight and Obesity in 195 Countries over 25 Years. $N$ Engl J Med 377: 13-27. [Crossref]

2. Flegal KM, Kit BK, Orpana H, Graubard BI (2013) Association of all-cause mortality with overweight and obesity using standard body mass index categories: a systematic review and meta-analysis. JAMA 309: 71-82. [Crossref]

3. Singh GM, Danaei G, Farzadfar F, Stevens GA, Woodward M, et al. (2013) The agespecific quantitative effects of metabolic risk factors on cardiovascular diseases and diabetes: a pooled analysis. PloS One 8: e65174-e65174.

4. Emerging Risk Factor Collaboration (2011) Separate and combined associations of body-mass index and abdominal adiposity with cardiovascular disease: Collaborative analysis of 58 prospective studies. Lancet 377: 1085-1095.

5. Lauby-Secretan B, Scoccianti C, Loomis D, Grosse Y, Bianchini F, et al. (2016) Body Fatness and Cancer-Viewpoint of the IARC Working Group. N Engl J Med 375: 794798. [Crossref] 
6. Abdullah A, Wolfe R, Stoelwinder JU, de Courten M, Stevenson C, et al. (2011) The number of years lived with obesity and the risk of all-cause and cause-specific mortality. Int J Epidemiol 40: 985-996. [Crossref]

7. Lee JM, Pilli S, Gebremariam A, Keirns CC, Davis MM, et al. (2010) Getting heavier, younger: trajectories of obesity over the life course. Int J Obes (Lond) 34: 614-623. [Crossref]

8. Everhart JE, Pettitt DJ, Bennett PH, Knowler WC (1992) Duration of obesity increases the incidence of NIDDM. Diabetes 41: 235-240. [Crossref]

9. Eastwood PR, Malhotra A, Palmer RL, Horner RL, Thurnheer R, et al (2010). Obstructive sleep apnoea: from pathogenesis to treatment. Current controversies and future directions. Respirology 15: 587-595.

10. Spicuzza L, Caruso D, Di Maria G (2015) Obstructive sleep apnoea syndrome and its management. Ther Adv Chronic Dis 6: 273-285. [Crossref]

11. American Academy of Sleep Medicine (2005) International classification of Sleep Disorders. Diagnostic and Coding Manual. Second edition. Westchester, III: American Academy of Sleep Medicine.

12. Memtsoudis SG, Besculides MC, Mazumdar M (2013) A rude awakening-the perioperative sleep apnea epidemic. $N$ Engl J Med 368: 2352-2353. [Crossref]

13. Park JG, Ramar K, Olson EJ (2011) Updates on definition, consequences, and management of obstructive sleep apnea. Mayo Clin Proc 86: 549-554. [Crossref]

14. Johson EO, Roth T (2006) An epidemiologic study of sleep disordered breathing symptoms among adolescents. Sleep 29: 1135-1142.

15. Kielb SA, Ancoli-Israel S, Rebok GW, Spira AP (2012) Cognition in obstructive sleep apnea-hypopnea syndrome (OSAS): current clinical knowledge and the impact of treatment. Neuromed Med 14: 1-20.

16. Eckert DJ, Malhotra A (2008) Pathophysiology of adult obstructive sleep apnea. Proc Am Thorac Soc 5: 144-153. [Crossref]

17. Osman AM, Carter SG, Carberry JC (2018) Obstructive sleep apnea: current perspectives. Nat Sci Sleep 10: 21-34. [Crossref]

18. Eastwood PR, Szollosi I, Platt PR, Hillman DR (2002) Collapsibility of the upper airway during anesthesia with isoflurane. Anesthesiology 97: 786-793.

19. Ito E, Tsuiki S, Maeda K, Okajima I, Inoue Y (2016) Oropharyngeal Crowding Closely Relates to Aggravation of OSA. Chest 150: 346-352. [Crossref]

20. White DP (2006) Sleep apnea. Proc Am Thorac Soc 3: 124-128. [Crossref]

21. Marcus CL, Moore RH, Rosen CL, Giordani B, Garetz SL, et al. (2013) A randomized trial of adenotonsillectomy for childhood sleep apnea. N Engl J Med 368: 2366-2376. [Crossref]

22. McGinley BM, Schwartz AR, Schneider H, Kirkness JP, SmithPL, et al. (2008). Upper airway neuromuscular compensation during sleep is defective in obstructive sleep apnea. J Appl Physiol 105: 197-205.

23. Sands SA, Eckert DJ, Jordan AS, Edwards BA, Owens RL, et al. (2014) Enhanced upper airway muscle responsiveness is a distinct feature of overweight/obese individuals without sleep apnea. Am J Respir Crit Care Med 190: 930-937.

24. Eckert DJ, Malhotra A, Lo YL, White DP, Jordan AS (2009) The influence of obstructive sleep apnea and gender on genioglossus activity during rapid eye movement sleep. Chest 135: 957-964. [Crossref]

25. Tagaito Y, Isono S, Remmers JE, Tanaka A, Nishino T (2007) Lung volume and collapsibility of the passive pharynx in patients with sleep-disordered breathing. $J \mathrm{Appl}$ Physiol 103: 1379-1385. [Crossref]

26. Schwartz AR, Patil SP, Laffan AM, Polotsky U, Schneider H, et al. (2008) Obesity and obstructive sleep apnea. Pathogenic mechanisms and therapeutic approaches. Proc Am Thorac Soc 5: 186-192.

27. Larkin EK, Patel SR, Redline S, Mignot E, Elston RC, et al. (2006) Apolipoprotein E and obstructive sleep apnea: evaluating whether a candidate gene explains a linkage peak. Genet Epidemiol 30: 101-110.

28. Polotsky VY, O’Donnell CP (2007) Genomics of sleep-disordered breathing. Proc Am Thorac Soc 4: 121-126.

29. Drazen JM, Phimister EG (2007) Publishing genomewide association studies. $N$ Engl J Med 357: 496.

30. Schwartz RJ, Pasirstein M, Kaplan J, Pierson R, Mackley A, et al. (2006) Family aggregation of upper airway soft tissue structures in normal subjects and patients with sleep apnea. Am J Respir Crit Care Med 173: 453-463.
31. Larkin EK, Patel SR, Goodloe RJ, Li Y, Zhu X, et al. (2010) A candidate gene study of obstructive sleep apnea in European Americans and African Americans. Am J Respir Crit Care Med 182: 947-953. [Crossref]

32. Gozal D, Kheirandish-Gozal L (2008) Cardiovascular morbidity in obstructive sleep apnea: oxidative stress, inflammation an much more. Am J Respir Crit Care Med 177 369-375.

33. Punjabi NM, Shahar E, Redline S, Gottlieb DJ, Givelber R, et al. (2004) Sleepdisordered breathing, glucose intolerance, and insulin resistance: the Sleep Hearth Health Study. Am J Epidemiol 160: 521-530.

34. Staiger H, Tschritter O, Machann J, Thamer C, Fritsche A, et al. (2003) Relationship of serum adiponectin and leptin concentrations with body fat distribution in humans. Obes Res 11: 368-372. [Crossref]

35. Chen K, Li F, Li J, Cai H, Strom S, et al. (2006) Induction of leptin resistance through direct interaction of C-reactive protein with leptin. Nat Med 12: 425-432.

36. Punjabi NM, Beamer BA (2007) C-reactive protein is associated with sleep disordered breathing independent of adiposity. Sleep 30: 29-34.

37. Tasali E, Ip M (2008) Obstructive sleep apnea and metabolic syndrome: alterations in glucose metabolism and inflammation. Proc Am Thorac Soc 153: 207-217.

38. Sand SA, Edwards BA, Kelly BJ, Skuza EM, Dadvison MR, et al. (2010) Mechanism underlying accelerated arterial oxygen desaturation during recurrent apnea. Am J Respir Crit Care Med 182: 961-969.

39. Chamberlin L (2013) Brain circuitry mediating arousal from obstructive sleep apnea Curr Opin Neurobiol 23: 774-779.

40. Jordan AS, O'Donoghue FJ, Cori JM, et al. (2017) Physiology of Arousal in Obstructive Sleep Apnea and Potential Impacts for Sedative Treatment. Am J Respir Crit Care Med 196: 814-821. [Crossref]

41. Gray EL, Mckenzie DK, Eckert DJ (2017) Obstructive sleep apnea without obesity is common and difficult to treat: evidence for a distinct pathophysiological phenotype. $J$ Clin Sleep Med 13: 81-88.

42. Preston SH, Vierboom YC, Stokes A (2018) The role of obesity in exceptionally slow US mortality improvement. Proc Natl Acad Sci U S A 115: 957-961. [Crossref]

43. Huang Y, White DP, Malhotra A (2007) Use of computational modeling to predict responses to upper airway surgery in obstructive sleep apnea. Laryngoscope 117: 648653

44. Marcus CL, Fernandes Do Prado LB, Lutz J, Katz ES, Black CA, et al. (2004) Developmental changes in upper airway dynamics. J Appl Physiol (1985) 97: 98-108. [Crossref]

45. Cintra F, Tufik S, D'Almeida V, Calegare BFA, de Paola A, et al. (2011) Cysteine: a potential biomarker for obstructive sleep apnea. Chest 139: 246-252. [Crossref]

46. Iber C, Ancoli-Israel S, Chesson AL, Quan SF (2007) The AASM Manual for the Scoring of Sleep and Associated Events. Westchester, IL: American Academy of Sleep Medicine.

47. Martínez-García MA, Soler-Cataluna JJ, Ejarke-Marínez I, Soriano Y, Roman-Sánchez $\mathrm{P}$, et al. (2009) Continuous positive airway pressure treatment reduces mortality in patients with ischemic stroke and obstructive sleep apnea: a 5-years follow-up study. Am J Respir Crit Care Med 180: 36-41.

48. Collop NA, Anderson WM, Boehlecke B, Claman D, Goldberg R, et al. (2007) Clinical guidelines for the use of unattended portable monitors in the diagnosis of obstructive sleep apnea in adult patients. Portable Monitor Task Force of the American Academy of Sleep Medicine. J Clin Sleep Med 3: 737-747.

49. Brooks M (2017) Disposable skin patch detects sleep apnea at home. Medscape News $\&$ Perspective.

50. Sleep (2017) 31st Annual Meeting of the Associate Professional Sleep Societies. Abstract 0448.

51. Fanney RJ, Walker BS, Farnes RM, Snow GL, Walker JM (2011) The Stop-Bang equivalent model and prediction of severity of obstructive sleep apnea: relation to polysomnographic measurement of the apnea/hypopnea index. J Clin Sleep 7: 459-463.

52. Libman E, Bailes S, Fichten CS, Rizzo D, Creti L, et al. (2017) CPAP Treatment Adherence in Women with Obstructive Sleep Apnea. Sleep Disord 2017: 2760650. [Crossref]

53. Kushida CA, Chediak A, Berry RB, Brown LK, Gozal D, et al. (2008) Clinical guidelines for manual titration of positive airway pressure in patients with obstructive sleep apnea. J Clin Sleep Med 4: 157-171. 
54. Kushida CA, Littner MR, Hirshkowitz M, Morgenthaler TI, Alessi CA, et al. (2006) Practice parameters for the use of continuous and bilevel positive airway pressure device to treat adult patients with sleep-related breathing disorders. Sleep 29: 375-380.

55. Sharma SK, Agrawal S, Damodaran D, Sreenivas V, Kadhiravasn T, et al. (2011) CPAP for the metabolic syndrome in patients with obstructive sleep apnea. $N$ Engl J Med 365: $2277-2286$

56. Lin HS, Zuliani G, Amjad EH, Prasad AS, Badr MS, et al. (2007) Treatment compliance in patients lost the follow-up after polysomnography. Otolaryngol Head Neck Surg 136: 236-249.

57. Gay PC, Harold DL, Olson EJ (2003) A randomized double-blind clinical trial comparing continuous positive airway pressure with a novel bilevel pressure system for treatment of obstructive sleep apnea syndrome. Sleep 26: 864-869.

58. Greenburg DL, Lettieri CJ, Eliasson AH (2009) Effects of surgical weight loss on measures of obstructive sleep apnea: a meta-analysis. Am J Med 122: 535-542. [Crossref]

59. Ferguson KA, Cartwright R, Rogers R, Schmidt-Nowara W (2006) Oral appliances for snoring and obstructive sleep apnea: a review. Sleep 29: 244-262. [Crossref]

60. Tsai WH, Vazquez JC, Oshima T, Dort L, Roycroft B, et al. (2004) Remotely controlled mandibular positioner predicts efficacy of oral appliances in sleep apnea. Am J Respir Crit Care Med 170: 366-370.

61. Jun JC, Chopra S, Schwartz AR (2016) Sleep apnoea. Eur Respir Rev 25: 12-18. [Crossref]

62. Strollo PJ, Gillespie MB, Soose RJ, Maurer JT, de Vries N, et al. (2015) Upper airway stimulation for obstructive sleep apnea: durability of the treatment effect at 18 months. Sleep 38: 1593-1598

63. Strollo PJ Jr, Soose RJ, Maurer JT, de Vries N, Cornelius J, et al. (2014) Upper-airway stimulation for obstructive sleep apnea. N Engl J Med 370: 139-149. [Crossref]

64. Tuomilehto H, Seppä J, Uusitupa M (2013) Obesity and obstructive sleep apnea-clinical significance of weight loss. Sleep Med Rev 17: 321-329. [Crossref]

65. Sarkhosh K, Switzer NJ, El-Hadi M, Birch DW, Shi X, et al. (2013) The impact of bariatric surgery on obstructive sleep apnea: a systematic review. Obes Surg 23: 414423. [Crossref]

66. Ashrafian H, Toma T, Rowland S, Harling L, Tan A, et al. (2015) Bariatric surgery and no surgery weight loss for obstructive sleep apnoea? A systematic review and comparison meta-analyses. Obes Surg 25:1239-1250.

67. Dempsey JA, Veasey SC, Morgan BJ, O'Donnell CP (2010) Pathophysiology of sleep apnea. Physiol Rev 90: 47-112. [Crossref]

68. Powell N (2005) Upper airway surgery does have a major role in the treatment of obstructive sleep apnea "the tail end of the dog". Pro J Clin Sleep Med 1: 236-240. [Crossref]

69. Michels Dde S, Rodrigues Ada M, Nakanishi M, Sampaio AL, Venosa AR (2014) Nasal involvement in obstructive sleep apnea syndrome. Int J Otolaryngol 2014: 717419. [Crossref]

70. Carroll W, Wilhoit C, Intaphan J, Nguyen S, Guillespie M (2012) Snoring management and nasal surgery and upper airway radiofrequency ablation. Otolaryngol Head Neck Surg 146: 1023-1027.

71. White DP (2016) Pharmacologic Approaches to the Treatment of Obstructive Sleep Apnea. Sleep Med Clin 11: 203-212. [Crossref]

72. Horner RL, Grace KP, Wellman A (2017) A resource of potential drugs target and strategic decision-making for obstructive sleep apnea pharmacotherapy. Respirology 22: 861-873.

73. Taranto-Montemurro L, Sands SA, Edwards BA, Azarbarzin A, Marques M, et al. (2016) Desipramine improves upper airway collapsibility and reduces OSA severity in patients with minimal muscle compensation. Eur Respir J 48: 1340-1350.

74. Carberry JC, Fisher LP, Grunstein RR, Gandevia SC, et al. (2017) Role of common hypnotics on the phenotypic causes of obstructive sleep apnoea: paradoxical effects of zolpidem. Eur Respir J 50:1. [Crossref]

75. Roizenbaltt S, Guilleminault C, Poyares D, Cintra F, Kauati A, et al. (2006) A doubleblind, placebo-controlled, crossover study of sildenafil in obstructive sleep apnea. Arch Inter Med 166: 1763-1767.

76. Schwartz JR, Hirshkowitz JR, Matheson JK (2003) Modafinil as adjunct therapy for daytime sleepiness in obstructive sleep apnea: a 12-week, open-label study. Chest 124 : 2192-2199.
77. Rich J, Raviv A, Raviv N, Brietzke SE (2012) All-cause mortality and obstructive sleep apnea severity revisited. Otolaryngol Head Neck Surg 147: 583-587.

78. Campos-Rodríguez F, Martínez-García MA, de la Cruz Moron I, Almeida-González C, Catalán-Serra P, et al (2012) Cardiovascular mortality in women with obstructive sleep apnea with and without continuous positive pressure treatment: a cohort study. Ann Intern Med 156: 115-122.

79. Martínez-García MA, Campos-Rodríguez F, Catalán-Serra P, Soler-Cataluna JJ, Almeida-González C, et al. (2012). The cardiovascular mortality in obstructive sleep apnea in the elderly: role of long-term continuous positive airway pressure treatment: a prospective observational study. Am J Respir Crit Care Med 186: 909-916.

80. Mehra R, Stone KL, Varosy PD, Hoffman AR, Marcus GM, et al. (2009) Nocturnal arrhythmias across a spectrum of obstructive and central-sleep disordered breathing in older men: outcomes in sleep disorders in older men (MrOS) sleep) study. Arch Inter Med 169: 1147-1155.

81. Drager LF, Polotsky VY, Lorenzi-Filho G (2011) Obstructive sleep apnea: an emerging risk factor for atherosclerosis. Chest 140: 534-542. [Crossref]

82. Yaggi HK, Concato J, Kernan WN, Lichtman JH, Brass LM, et al. (2005) Obstructive sleep apnea as a risk factor for stroke and death. $N$ Engl $J$ Med 353: 2034-2041. [Crossref]

83. Golbin JM, Somers UK, Caples SM (2008) Obstructive sleep apnea, cardiovascular disease, and pulmonary hypertension. Proc Am Thorac Soc 5: 2000-2006.

84. Ghosh D, Jamson SL, Baxter PD, Elliot MW (2012) Continuous measures of driving performance on an advanced office-based driving simulator can be used to predict simulator task failure in patients with obstructive sleep apnea. Thorax 67: 815-821.

85. Weitzenblom E, Chaouat A, Kessler R, Canuet M (2008) Overlap syndrome: obstructive sleep apnea in patients with chronic obstructive pulmonary disease. Proc Am Thorac Soc 5: 237-241.

86. Keller DM (2013) Childhood asthma raises risk for adult sleep apnea. Medscape Medical News. June 6- American Thoracic Society (ATS). International Conference.

87. Raghu G, Rochwerg B, Zhang Y, García CA, Azuma A, et al. (2015) An official ATS ERS/JRS/ALAT Clinical Practice Guidelines treatment of idiopathic pulmonary fibrosis. An update of 2011. Clinical practice guideline. Am J Respir Crit Care Med 192: e3-19.

88. Manni R, Terzaghi M, Arbasino C, Sartori I, Galimberti CA, et al. (2003) Obstructive sleep apnea in a clinical series of adult epilepsy patients: frequency and features of the comorbidity. Epilepsia 44: 836-840.

89. Nieto FJ, Peppard PE, Finn L, Hia KM, Farré R (2012) Sleep disorders breathing and cancer mortality: results from the Wisconsin Sleep Cohort Study. Am J Respir Crit Care Med 186: 190-194.

90. Piper AJ, Yee BJ (2014) Hypoventilation syndromes.Compr Physiol 4: 1639-1676. [Crossref]

91. Mokhlesi B, Tulaimat A (2007) Recent advances in obesity hypoventilation syndrome Chest 132: 1322-1336. [Crossref]

92. Balachandran JS, Masa JF, Mokhlesi B (2014) Obesity hypoventilation syndrome epidemiology and diagnosis. Sleep Med Clin 9: 341-347.

93. Piper AJ, Grunstein RR (2007) Current perspective of the obesity hypoventilation syndrome. Curr Opin Pulm Med 13: 490-496.

94. Mokhlesi B, Tulaimat A, Faibusswitsch I, Wang Y, Evans AT (2007) Obesity hypoventilation syndrome: prevalence and predictors in patients with obstructive sleep apnea. Sleep Breath 11: 117-124

95. Powers MA (2008) The obesity hypoventilation syndrome. Respir Care 53: 1723-1730. [Crossref]

96. Weitzenblum E, Kessler R, Canuet M, Chaouat A (2008) Obesity-hypoventilation syndrome. Rev Mal Respir 25: 391-403. [Crossref]

97. Alvarado A (2017) Domiciliary oxygen: facts and fallacies. Clin Res Trials 3: 1-10.

98. Katyal N, Bollu PC (2018) Ventilation, obesity-hypoventilation syndrome. (Update 2018 Feb 15). In: StarlPearls (Internet). Treasure Island (FL): StatPearls publishing.

99. Masa JF, Corral J, Alonso ML, Ordax E, Troncoso MF, et al. (2015) Spanish sleep network. Efficacy of different treatment alternatives for Obesity Hypoventilation Syndrome. Pickwick study. Am J Respir Crit Care Med 192: 86-95. 
100. Windisch W, Dreher M, Geiseler J, Siemon K, Brambring J, et al. (2017) Guidelines for Non-Invasive and Invasive home mechanical ventilation for treatment of chronic respiratory failure-Update 2017. Pneumologie 71: 722-795.

101. Msaad S, Kammoun S, Haykacem F, Kammoun R, Masmoudi K, et al. (2018) Reflections on obesity hypoventilation syndrome. J Sleep Disord Ther 7: 1.

102. To T, Stanojevic S, Moores G, Gerson AS, Bateman ED, et al. (2012) Global asthma prevalence in adults: finding from the croos-sectional World Health Survey. NMC Public Health 12: 204.

103. Beuther OA, Sutherland ER (2007) Overnight, obesity, and incident asthma. A metaanalysis of prospective epidemiologic studies. Am J Respir Crit Care Med 175: 161166

104. Boulet LP (2013) Asthma and obesity. Clin Exp Allergy 43: 8-21. [Crossref]

105. Israel E, Reddel HK (2017) Severe and Difficult-to-Treat Asthma in Adults. $N$ Engl J Med 377: 965-976. [Crossref]
106. Moore WC, Meyers DA, Wenzel SE, Tedque WD, Li H, et al. (2010). Identification of asthma phenotypes using cluster analysis in the Severe Asthma Research Program. Am J Respir Crit Care Med 181: 315-323.

107. Sutherland TJT, Cowan JO, Young S, Goulding A, Grant AM, et al. (2008) The association between obesity and asthma: interaction between systemic and airway inflammation. 168: 469-475.

108. Chen Z, Salam MT, Alderete TL, Habre R (2017) Effects of Childhood Asthma on the Development of Obesity among School-aged Children. Am J Respir Crit Care Med 195: 1181-1188. [Crossref]

109. Alvarado A (2017) Dual bronchodilator therapy. Clin Res Trials 3: 1-12.

110. Shore SA (2008) Obesity and asthma: possible mechanisms. J Allergy Clin Immunol 121: 1087-1093. [Crossref]

111. Desadi D, Brightling G (2014) Reply: elevated sputum IL-5 and submucosal eosinophilia in obese individuals with severe asthma. Am J Respir Crit Care Med 189: 1286 .

Copyright: (C2018 Alvarado A. This is an open-access article distributed under the terms of the Creative Commons Attribution License, which permits unrestricted use, distribution, and reproduction in any medium, provided the original author and source are credited. 